\title{
Life Expectancy as Indicator of Health Status: The Case of Edmonton and Calgary
}

\author{
Kwame Boadu \\ Department of Sociology \\ University of Alberta
}

\begin{abstract}
This study compares the health status of the populations of Calgary and Edmonton by examining their respective life expectancies. Age- and causespecific death rates are analysed by the method of standardization and decomposition. The analysis reveals that generally, the population of Calgary enjoys a higher life expectancy than the population of Edmonton, and by implication, better health status. However, decomposition by age-groups reveals that females aged 65 years and over in Edmonton are healthier than females of the same age-group in Calgary. Similarly, when decomposition by cause-of death is applied, there are instances where death rates due to certain cause-ofdeath components are higher in Calgary than in Edmonton when the general population is considered as well as sub-groups. The results of the study bring to the fore the inherent limitation of life expectancy as a true reflection of the health status of an entire population, and particularly the two populations of Calgary and Edmonton.
\end{abstract}




\section{Résumé}

La présente étude compare l'état de santé des populations de Calgary et d'Edmonton en examinant leurs espérances de vie respectives. Les taux de mortalité par âge et par cause sont analysés selon le mode de standardisation et de décomposition. L'analyse révèle que la population de Calgary jouit en général d'une durée de vie plus longue que celle d'Edmonton et, partant, d'un meilleur état de santé. Cependant, la décomposition par âge révèle que les Edmontoniennes âgées de 65 ans révolus sont en meilleure santé que leurs congénères de Calgary. Pareillement, selon la méthode de décomposition par âge, il existe des cas où certains facteurs de mortalité sont plus élevés à Calgary qu'à Edmonton quand l'analyse porte à la fois sur la population générale et les sous-groupes. Ces résultats illustrent les limites inhérentes de l'espérance de vie utilisée pour déterminer l'état de santé de toute une population - celles de Calgary et d'Edmonton en particulier.

Key words: Expectation of Life, Cause-of-Death, Standardization, Decomposition

\section{Introduction}

This study examines the health status of the populations of Calgary and Edmonton using their respective life expectancies as indicator. Life expectancy is employed because it is an internationally recognized indicator of population health (Shryock, H. S. et al., 1973). It reflects the extent to which people are healthy and free of life-threatening illnesses, have adequate nutrition and access to health care, and live in an environment free of hazards which may shorten life. This is not to claim that life expectancy is the only index that reflects the health status of a population and for that matter, any particular group. Other measures such as self-reported health, infant mortality, chronic diseases, quality of health services, etc. all are variously used as indicators of the health status of a population.

On the basis of above, it can be said that the population of Alberta is one of the healthiest, because studies indicate that Albertans have one of the highest life expectancies in Canada and the world. It is noted that over the past century, the life expectancy in Alberta has increased steadily. Fifty years ago, the average life expectancy was 65 years for men and 68 years for women. Currently, life expectancy is about 10 years longer for men and 13 years for women (Alberta 
Health, 1996). According to Alberta Health, in 1991 life expectancy of Albertans was 75.1 years for males and 81.2 years for females. By 1994, life expectancy for males was 75.5 years and 81.4 years for females. Among Canadian provinces, it is noted that Alberta ranks third in life expectancy, behind Saskatchewan and British Columbia.

Correspondingly, and as already mentioned, Albertans generally enjoy good health compared with other Canadians. Studies indicate that almost two out of three Albertans, men and women alike, report that their health is very good or excellent in comparison to the health of others their age. This proportion, according to Alberta Health, has increased slowly and currently is somewhat higher than the Canadian average. However, the fact still remains that inequalities in health exist in Alberta as in virtually all societies.

Any discussion of life expectancy as-a-measure-of health_status-would be made even more meaningful taking cognizance of the linkage between health status and socioeconomic status. Poverty, unemployment, education, etc. all significantly affect health status (Frank and Mustard, 1994) and hence, life expectancy. One of the best sources of historical information illustrating the link between health and socioeconomic status is the Black Report of the U.K Office of Population Census and Surveys which showed an inverse relationship between mortality and socioeconomic class across the entire population, that goes back to the beginning of this century (Hertzman et al., 1990). There are, of course, several other studies which support this linkage (see, for example, Marmot and Theorell, 1988).

The case of Alberta is no different. Alberta Health (1996) reports that the health status of Albertans appear to vary with social and economic conditions, as well as with geographic differences. The development of life skills through education and training increases opportunities for income and job security, and enhances life management potential, the ability to cope with change, and a sense of control over life circumstances. These are key factors that influence health status. In general, as people's income increases, so do indicators of good health. Albertans with larger household incomes report being healthier than those with smaller incomes. For example, in 1996, $76 \%$ of Albertans in the highest income group reported good or excellent health, but only $46 \%$ of those in the lowest income group reported similar good health.

Also, as people's level of education rises, so does their self-reported health status. Albertans with more years of formal education report better health than those with less formal education. According to Alberta Health (1996), 78\% of Albertans with university-level education report good or excellent health, in comparison to $68 \%$ of those with technical/vocational education and only $54 \%$ of those with high school education or less. It must be pointed out, however, that self-rated health by educational attainment may be confounded by age differences across education levels. There is also evidence that a gradient exists 
in the rate of disease from the top of the social hierarchy to the bottom for almost every disease that has been studied, practically everywhere in the world (Syme, 1994). Higher-income people tend to live longer than lower-income people. Moreover, people on one rung live longer than those on the rung below them, on the entire socioeconomic ladder.

It is common knowledge that a key determinant of income is employment. Generally, people who are employed enjoy better health than those who are unemployed. People with more control over their work conditions, fewer lessrelated demands on the job, and greater workplace social supports are generally healthier. When employees have the opportunity to use their skills and abilities in the workplace, and when their work helps enhance their sense of self-esteem and achievement, they are, as a group, at lower health risk.

On the other hand, unemployment can significantly influence mental, physical and social health. Research on the health impacts of unemployment shows that in most age-groups, mortality appears to increase as the unemployment rate rises (Brenner, M. H., 1979). A review of global research on unemployment and health found that "high levels of unemployment and economic instability cause a significant increase in the levels of mental ill-health and also, have adverse effects on the physical health, not only of the unemployed but also of their families and the community in general" (Westcott, $G$ et al., 1985).

A relatively new body of research has shown that per capita income growth is no longer as important a factor in determining overall health status as income distribution. Data compiled by Wilkinson and other researchers show that after a country achieves a per capita GNP of approximately $\$ 5,000$ (in 1990 values), overall life expectancy depends more on the internal distribution of wealth than increases in income (Wilkinson, 1994). The narrower the spread of income in a given society, the higher will be its overall health status. Using life expectancy as a barometer for health, Wilkinson observes that countries with the longest life expectancy are not necessarily the wealthiest. Those countries with the smallest spread of incomes and the smallest proportion of the population in relative poverty are usually the ones who have the highest life expectancy, as for example, Japan.

As regards geographic differences in health status, Alberta Health (1996) observes that Albertans in Edmonton and northern areas generally report poorer health than those in Calgary and southern areas of the province. An analysis of 1990-92 health data reveals that a male newborn living in Calgary has a life expectancy of 75.9 years, two years longer than his counterpart in northern Alberta. Similarly, the remaining life expectancy of his 25 -year-old mother is more than 6 months longer than that of her counterpart in the north. 
That health status as reflected in expectation of life appears to vary with social and economic conditions, as well as with geographic differences is not uncommon (see also, Marmot et al,, 1991). What perhaps, is lacking in the literature particularly, with reference to the case of Alberta is some form of analysis which attempts to examine the relative contribution of age- and/or cause-specific death rate to overall expectation of life, and how their variability are reflected in the health status of the general population and across the various age groups. This study sets out to achieve just that. The study compares the health status of the populations of Calgary and Edmonton using their respective life expectancies. Following from the analysis, the study would comment on the reliability of life expectancy as a true reflection of the overall health status of a population.

\section{Data-and Methods}

The populations of the regional health authorities of Calgary and Edmonton constitute the unit of analysis in this study. The data used in the analysis is the age-specific and cause-specific death rates of the population of the two health regions for the period 1989-1993. This information was compiled by the Health Surveillance Division of Alberta Health. The mid-year population of 1991 is chosen as basis for the analysis since it represents the mid-point of the period covered by the data. The populations of these two regional health authorities are used for the study because together, they account for more than half the total population of the province of Alberta thus having the benefit of a large sample. An added advantage is that it provides a somewhat fair representation of the populations of both the northern and southern portions of the province, though not fair in all characteristics.

The Calgary Regional Health Authority comprises the population of Calgary and those of some fifty-four adjacent communities, whilst the Capital Regional Health Authority comprises the population of Edmonton and that of some sixtythree other surrounding areas. In 1991, whereas the total population of the province was $2,545,555$, the two health regions combined for a total of $1,412,920$, representing 55\% (Statistics Canada, 1991). The Calgary health region contains a slightly higher population than the Capital health region of Edmonton, 754,035 and 658,890 respectively.

In both health regions, females outnumber males. There are 375,930 males as against 378,105 females in Calgary. For Edmonton, there are 326,160 males and 332,730 females (appendix A). But in the two regions, males register more deaths than females. Of the total 17,612 deaths recorded in Calgary for the period 1989-93, male deaths numbered 9,238 and female deaths were 8,374 (appendix B). Similarly for Edmonton, male and female deaths were 10,153 and 8,506 respectively, of the total 18,659 deaths recorded for the same period (appendix C). In this study, the age-specific death rates are calculated for 5-year 


\section{K. Boadu}

age groups except for the first year of life. But for the purposes of comparison and decomposition analysis, four broad age groups, namely, 0-14, 15-39, 40-65 and 65 and over are considered.

Also, seven cause-of-death components are used in this study and are identified as follows: (1) infectious and parasitic diseases; (2) neoplasm; (3) diseases of the circulatory system; (4) diseases of the respiratory system; (5) diseases of the digestive system; (6) injury and poisoning; and (7) all other causes of death.

\section{Decomposition Analysis}

I investigate the question by employing a statistical method of standardization and decomposition developed by Das Gupta (1993). To illustrate the procedure employed in this analysis, I will consider a decomposition of the difference in expectation of life at birth into two components representing the contribution of age-specific death rates (ASDRs) under age 15 and that of above age 15. Let " $A$ " represent the vector of ASDRs below age 15 (i.e., ASDRs for age-groups 0 , $1-4,5-9$ and 10-14) and "B" the vector of ASDRs above age 15 for Calgary. Similarly, I define two vectors " $a$ " and " $b$ " for Edmonton. Now, it can be said that the expectation of life at birth in Calgary is a function of two vectors " $A$ " and " $B$ " or $F(A, B)$, which stands for the process of calculating $e^{0}$ using the standard life table technique. Thus,

$$
\begin{aligned}
& \mathrm{e}^{0}(\text { Calgary })=F(A, B), \text { and } \\
& \left.e^{0} \text { (Edmonton }\right)=F(a, b)
\end{aligned}
$$

In order to decompose the difference between the two expectations of life, I define and calculate $F(A, b)$ and $F(a, B)$ also. $F(A, b)$ is the expectation of life at birth obtained by constructing a life table with ASDRs under age 15 from Calgary and ASDRs above age 15 from Edmonton. $\mathrm{F}(\mathrm{a}, \mathrm{B})$ is also defined in a similar fashion. Following from above, the difference in expectation of life can be decomposed into two components:

$$
\begin{aligned}
\text { Difference in } \mathrm{e}^{\mathrm{o}} & =\mathrm{F}(\mathrm{A}, \mathrm{B})-\mathrm{F}(\mathrm{a}, \mathrm{b}) \\
& =.5[\mathrm{~F}(\mathrm{a}, \mathrm{b})-\mathrm{F}(\mathrm{a}, \mathrm{B})+\mathrm{F}(\mathrm{A}, \mathrm{b})-\mathrm{F}(\mathrm{A}, \mathrm{B}) \\
& +.5[\mathrm{~F}(\mathrm{a}, \mathrm{b})-\mathrm{F}(\mathrm{A}, \mathrm{b})+\mathrm{F}(\mathrm{a}, \mathrm{B})-\mathrm{F}(\mathrm{A}, \mathrm{B})]
\end{aligned}
$$

$F(a, b)-F(a, B)$ as well as $F(a, B)-F(A, B)$ will be different from zero only if the ASDRs above age 15 are different. And so both of these may be attributed to the difference in ASDRs above age 15 in the two health regions. The average of these two is taken to be the contribution of death rates above age 15 to the difference in $e^{\circ}$. Similarly, the second component can be seen to represent the contribution of ASDRs under age 15. The sum of the two would add up to the total difference in expectation of life between the two populations. As for example, if one component represents the age-group under 15 years and the 
other above 15 years, each component would represent its net contribution to the difference in expectation of life at age zero if the ASDR in the other age-group were held constant (i.e., standardized). As a matter of fact, standardization enables us to measure the relative contribution of a particular age-group or a specific cause-of-death to the difference in expectation of life. In this study, if, with the exception of the under 15-year age-group, mortality rates in all other age-groups were equalized (standardized), one will be able to determine the relative contribution that mortality rate of the under 15-year age-group makes to the overall difference in life expectancy.

Similar method is used for decomposing the difference in expectation of life into components attributable to different causes of death. In this case, the vectors " $A$ " and " $B$ " are taken to be the cause-specific death rate by age. If a component has a positive value, this would mean it contributes positively to the overall differential in expectation of life. A negative value means that component makes a negative contribution to the overall gap in life expectancy.

In the analysis done, I first examine the relative contribution of each of the four age-groups to the differential in expectation of life between the two populations as a whole, and then between the male populations, and finally, between females. The procedure is repeated for the cause-of-death components to identify which of the seven causes is/are responsible for the gap in expectation of life.

\section{Results}

In Tables $1-6$, I take the difference in expectation of life at birth in Calgary and Edmonton and decompose the difference into components attributable to various age-groups and causes-of-death. In Table 1, it is observed that whereas the life expectancy of the population of Calgary is 79.09 years, the life expectancy of the population of Edmonton is 78.16 years, thus resulting in a difference of .94 years advantage for Calgary. Death rate in the age-group 40-64 of the population of Edmonton account for approximately 59 percent of the observed total difference in expectation of life between the two populations.

What this means, in effect, is that if death rates in the other age-groups were equalized or standardized except for death rate in the 40-64 age-group, the difference in expectation of life between the two populations would have been .55 years in favour of Calgary. In the same manner, death rate in the age-group 15-39 accounts for approximately 27 percent, while death rate in the $0-14$ agegroup accounts for approximately 12 percent of the total difference. Death rate in the 65 and over age-group accounts for approximately 3 percent of the total difference in expectation of life when death rates in the other age-groups are standardized. 


\section{Table 1}

\section{Difference Due to Decomposition by Age for Both Sexes Calgary and Edmonton: 1991}

\begin{tabular}{lcccc} 
Age Interval & \multicolumn{2}{c}{ Standardized $\mathrm{e}^{\circ *}$} & Difference & Percent \\
& Calgary & Edmonton & & \\
\hline $\mathbf{0 - 1 4}$ & 78.679 & 78.567 & 111 & 11.88 \\
$\mathbf{1 5 - 3 9}$ & 78.747 & 78.498 & .249 & 26.55 \\
$\mathbf{4 0 - 6 4}$ & 78.898 & 78.347 & .551 & 58.90 \\
$\mathbf{6 5 +}$ & 78.635 & 78.611 & .025 & 2.66 \\
All Ages & 79.092 & 78.156 & 936 & 100.00 \\
\hline
\end{tabular}

*These expectations of life are obtained by equalizing the age-specific death rates of Calgary and Edmonton for all age groups except those specified in column one.

When the analysis is interpreted for the male and female populations separately, a similar pattern as in the general population is observed in the case of males, however, there is some slight departure in the case of females. The observed total difference in expectation of life when only the male populations of the two health regions are examined is 1.38 years (see Table 2). This means that if death rates in this segment of the population only were examined while death rates in the female population were standardized, the gap in expectation of life between the two populations would be that much in favour of Calgary. An indication that overall, death rates in the male population of Edmonton is higher than in the male population of Calgary and thus contribute largely to the overall total negative gap for Edmonton.

On further inspection, it is revealed that death rate of the 40-64 year age-group accounts for approximately 55 percent of this difference. This means within the male population of Edmonton, the death rate of this age-group is responsible for a large proportion of the negative overall difference, followed by the 65 and over age-group (20\%), $15-39(19 \%)$ and the 0 -14 age-group (6\%). 


\section{Table 2 \\ Difference Due to Decomposition by Age for Males \\ Calgary and Edmonton: 1991}

\begin{tabular}{lccc} 
& \multicolumn{2}{c}{ Standardized $^{\circ}$} & Difference \\
Age Interval & Palgary Edmonton
\end{tabular}

\begin{tabular}{lcccc}
\hline $\mathbf{0 - 1 4}$ & 75.563 & 75.479 & .084 & 6.07 \\
$\mathbf{1 5 - 3 9}$ & 75.652 & 75.389 & .263 & 18.99 \\
\hline $\mathbf{4 0 - 6 4}$ & 75.899 & 75.140 & .758 & 54.78 \\
$\mathbf{6 5 +}$ & 75.659 & 75.380 & .279 & 20.16 \\
All Ages & 76.216 & 74.832 & 1.384 & 100.00 \\
\hline
\end{tabular}

For the female population (Table 3) on the other hand, the total difference is .35 years. This means that when death rates in the female populations only of the two health regions are examined while death rates in the male populations are standardized, the gap in expectation of life between the two populations would be a .35 years deficit for Edmonton, not quite a significant difference in absolute terms. Within the same female population, however, it is observed that the value of the difference of the age-groups 40-64, 15-3.9 and 0-14 all correspond with the positive total difference in favour of Calgary, but the 65 and over age-group posts a negative value. This is indicative that death rate is higher for females aged 65 and over in Calgary than in Edmonton, and if this age-group alone were to be examined while death rates in other age-groups were standardized, the overall difference in expectation of life would be positive for Edmonton.

In examining cause-specific death rates, it is observed in Table 4 that death rates due to neoplasm, diseases of the circulatory system, diseases of the digestive system, injury and poisoning and all other causes of death all correspond to the overall positive value of the difference in expectation of life in favour of Calgary. For these cause-of-death components, diseases of the circulatory system and injury and poisoning each account for relatively large proportions, 38 percent and 37 percent respectively, of the total difference when standardization is applied. These are followed by all other causes of death, neoplasm and diseases of the digestive system in that order. 
Table 3

Difference Due to Decomposition by Age for Females

Calgary and Edmonton: 1991

\begin{tabular}{lllll} 
Age Interval & \multicolumn{2}{c}{ Standardized $e^{\circ}$} & Difference & Percent \\
& Calgary & Edmonton & & \\
\hline $\mathbf{0 - 1 4}$ & 81.657 & 81.515 & .141 & 40.05 \\
$\mathbf{1 5 - 3 9}$ & 81.703 & 81.469 & .234 & 66.18 \\
$\mathbf{4 0 - 6 4}$ & 81.733 & 81.439 & .294 & 83.30 \\
$\mathbf{6 5 +}$ & 81.428 & 81.745 & -.316 & -89.53 \\
All Ages & 81.762 & 81.409 & .353 & 100.00 \\
\hline
\end{tabular}

On the other hand, the negative values of the differences of death rates due to infectious and parasitic diseases and diseases of the respiratory system indicate otherwise. In effect, what this means is that death rates due to infectious and parasitic diseases and diseases of the respiratory system are higher in Calgary than in Edmonton. As a result, when each of these is examined and death rates due to other cause-of-death components are standardized, overall life expectancy would be higher in Edmonton than in Calgary.

The pattern exhibited by death rates attributable to infectious and parasitic diseases and diseases of the respiratory system in the general population is again observed in the male population, although it is not very prominent in the case of death rates due to diseases of the respiratory system (see Table 5). For the remaining causes of death in the male population, diseases of the circulatory system account for the largest proportion of the total difference (45\%). This is followed by death rates due to injury and poisoning ( $28 \%)$, all other causes of death $(28 \%)$ and death rates due to neoplasm $(9 \%)$. 


\section{Table 4 \\ Difference Due to Decomposition by Cause of Death for Both Sexes, Calgary and Edmonton: 1991}

\begin{tabular}{ll} 
Cause of Death & \multicolumn{2}{c}{ Standardized $\mathrm{e}^{\circ *}$} & Difference & Percent \\
Calgary Edmonton &
\end{tabular}

Infectious \& Parasitic

Diseases

78.609

78.637

$-.028$

$-3.02$

Neoplasm

78.644

78.601

.043

4.57

Diseases of the

Circulatory System

78.801

78.444

.358

38.22

Diseases of the

Respiratory System

78.583

78.633

$-.081$

Diseases of the

Digestive System

78.637

78.609

.029

3.06

Injury \& Poisoning

78.798

78.448

.350

37.39

All Other Causes

78.756

78.490

.266

28.40

All Causes

79.092

78.156

.936

100.00

\footnotetext{
*These expectations of life are obtained by equalizing the cause-specific death rate of Calgary and Edmonton for all causes of death except those specified in column one.
} 


\section{Table 5}

\section{Difference Due to Decomposition by Cause of Death for Males, Calgary and Edmonton: 1991}

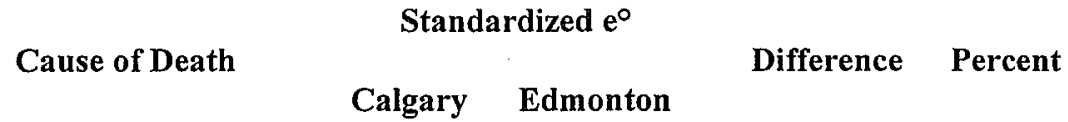

Infectious \& Parasitic

$\begin{array}{lllll}\text { Diseases } & 75.488 & 75.553 & -.065 & -4.67 \\ \text { Neoplasm } & 75.581 & 75.458 & .123 & 8.90\end{array}$

Diseases of the

Circulatory System

75.832

75.205

.627

45.30

Diseases of the

Respiratory System

75.510

75.531

$-.021$

$-1.52$

Diseases of the

Digestive System

75.544

75.496

.048

3.45

Injury \& Poisoning

75.716

75.322

.394

28.47

All Other Causes

75.658

75.380

.278

20.09

All Causes

76.216

74.832

1.384

100.00

In Table 6, it is observed that death rates attributable to injury and poisoning and all other causes of death account for 88 percent and 84 percent respectively, of the total difference in expectation of life between the female populations of the two health regions. These are followed by death rates attributable to infectious and parasitic diseases and diseases of the circulatory system in that order. However, the negative values of the difference of death rates attributable to neoplasm, diseases of the respiratory system and diseases of the digestive system do not follow the overall positive difference in expectation of life in favour of Calgary. As in previous cases, this is indicative that death rates 
attributable to all of these cause-of-death components are higher in Calgary than in Edmonton and when they are examined separately and other causes of death standardized, it would result in a higher expectation of life in favour of Edmonton over Calgary.

Table 6

Difference Due to Decomposition by Cause of Death for Females, Calgary and Edmonton: 1991

\section{Standardized $\mathrm{e}^{\circ}$ \\ Cause- of Death Difference Percent \\ Calgary Edmonton}

Infectious \& Parasitic

Diseases

81.59 .6

81.576

.020

5.59

Neoplasm

81.545

81.626

$-.082$

$-23.14$

Diseases of the

Circulatory System

81.593

81.578

.014

4.10

Diseases of the

Respiratory System

81.484

81.688

$-.204$

$-57.84$

Diseases of the

Digestive System

81.584

81.587

.004

$-1.00$

Injury \& Poisoning

81.741

81.430

.311

88.05

All Other Causes

81.735

81.437

.298

84.24

All Causes

81.762

81.409

.353

100.00 


\section{Discussion}

A variety of information may help explain the gap in expectation of life between the populations of the two health regions as revealed by the analyses. One such explanation can be traced to socioeconomic differences between the two populations. In both departments of income and education, Calgary enjoys some advantage over Edmonton. Whereas the proportion of the population earning less than $\$ 20,000$ in annual household income is $18 \%$ in Calgary, the proportion is $23 \%$ in Edmonton. Likewise, $46 \%$ percent of Edmonton's population has high school education or less compared to Calgary's $42 \%$ (appendix D). Not surprisingly, the 1991 census reports the unemployment rate among the male population of Edmonton as higher than that of the male population of Calgary $8.3 \%$ and $7.6 \%$ respectively, whereas the female unemployment rate is relatively the same in both regions $-8.4 \%$ for Calgary and $8.3 \%$ for Edmonton (Statistics Canada, 1995). The unemployment statistics quoted here refer to census metropolitan areas (CMAs) whose populations do not correspond exactly with those of the health regions, however, the figures provide some reasonable approximations for the purposes of this discussion. This argument may equally hold in the case of the aboriginal population to be discussed later on.

In regard to labour force participation, it is important to point out that unemployment has come to be interpreted as a major potential source of life stress with serious implication for family life and health as alluded to previously. Sismondo (1978) notes that unemployment has frequently been identified as a cause of various forms of social pathology, for example, crime, suicide and alcoholism, particularly in the wake of the Great Depression. "Unemployment did have a massive effect on death, illness, crime (particularly homicide), alcoholism and innumerable other social and personal pathologies ..." (Sismondo, 1978:35).

Brenner (1971:52) observes also that "among all specific causes of death, the strongest inverse relationship with index of employment are found for heart diseases, cardiovascular-renal disease, ulcers of stomach and duodenum, appendicitis, complications of pregnancy, fetal deaths, ..., acute poliomyelitis, hernia and intestinal obstruction and homicide and suicide." Further, Brenner notes that the 1.4 percent rise in unemployment during 1970 was directly responsible for some 51,570 total deaths, including 1,740 additional homicides, 1,540 additional suicides, and for 5,520 additional state mental hospitalizations .... (Brenner, 1977:4). This information adds to the evidence already advanced as the reasons underlying Edmonton's lower life expectancy relative to that of Calgary's.

Assigning reasons in respect of why the age-groups 40-64 and 15-39 account for large proportions of the observed difference in expectation of life, the argument can be made that these age-groups, and especially the 40-64 age-group form the 
bulk of the population which is most active both in terms of labour force participation and other activities as well. Being more active means greater exposure to high risk behaviours and health hazards as well as the possibility of greater exposure to more occupational hazards relative to populations in other age-groups. Based on all of factors discussed above, the indication is that socioeconomic standards in Calgary are relatively higher than in Edmonton and are a major contributory factor to the population's higher expectation of life compared to that of Edmonton.

A second important factor relates to the proportion of aboriginal populations contained in each health region (see appendix E). The aboriginal population in the CMA of Edmonton is almost three times the number in the CMA of Calgary and is a significant contributory factor to Edmonton's overall life expectancy and hence the population's relatively lower health status in comparison to Calgary. This is explained by the fact that in general, compared to other Canadians, the health status of aboriginal populations is quite low (Health Canada, 1996). Health Canada notes that in particular, housing and infrastructure are inferior in aboriginal communities and these conditions are known to be associated with a variety of health problems. These health problems, according to Health Canada, include infectious diseases, noninfectious respiratory diseases, chronic conditions and mental health conditions related to interpersonal conflicts.

Health Canada reports that in 1993, the mortality rate of First Nations, age standardized to the 1991 Canadian population, was 10.8 deaths per $1000,1.6$ times the Canadian rate of 6.9 . Similarly, the infant mortality rate among First Nations population was 10.9 deaths per 1000 live births, which is 1.7 times the national average of 6.3. It must be noted, as mentioned elsewhere that infant mortality rate is regarded as a significant indicator of socioeconomic conditions and therefore, health status of any population.

Among other observations, Health Canada reveals that the injury and poisoning death rate is 3.8 times higher in First Nations than in the rest of the Canadian population. As well, the circulatory disease death rate in First Nations is 1.3 times the Canadian rate and deaths due to respiratory diseases are 1.8 times higher. Infectious and parasitic disease mortality rates are 1.7 times higher in First Nations populations while suicide rates among men and women are 2.6 times and 4 times higher, respectively than the Canadian average. Also, it is reported that in 1992, the life expectancy of female aboriginals was estimated at 74.9 years, or six years less than the Canadian population. For males, life expectancy was estimated at 67.8 years in 1992 , or 6.8 years less than the Canadian population.

On the socioeconomic side, Health Canada (1996) reports the unemployment rate of First Nations as 27.7 percent, compared to the Canadian population unemployment rate of 10.3 percent in 1992 . The combined effect of all of above 
conditions means a significant lowering of life expectancy and hence, overall health status of any population, and for that matter the population of Edmonton given the large proportion of the aboriginal population.

In considering age- and cause-specific death rates, it was pointed out previously that death rates in the male population of Edmonton were responsible for a large proportion of the total negative difference in overall life expectancy between the two populations. This may suggest, on the other hand, that the female population in Edmonton is, after all, as healthy as their Calgary counterparts, if not better. This assertion is supported further by the observation that death rate for the female population aged 65 and over in Calgary is higher than in Edmonton and by implication, suggests females aged 65 and over in Edmonton have a higher expectation of life and therefore, enjoy better health status than females aged 65 and over in Calgary.

On the whole, the foregoing discussion brings to light the inherent limitation of the index of life expectancy as a measure of overall health status, though it is the most widely recognized indicator for such purpose. The revelation that females aged 65 years and over in Edmonton have a higher expectation of life than their counterpart age-group in Calgary and by implication, are healthier attests to this problem. The same argument could be made for death rates attributable to neoplasm, diseases of the respiratory system, as well as diseases of the digestive system where these are higher in Calgary than in Edmonton. These observations suggest that the higher expectation of life observed in Calgary does not necessarily translate into equal and/or better health status for the generality of the population of Calgary. It is obvious that there are variations in health status across different age-groups as well as between males and females. Neither does it suggest that the entire population of Calgary is healthier than the entire population of Edmonton.

\section{Conclusion}

This study compared the health status of the two populations of Calgary and Edmonton using their respective life expectancies. The analysis employed standardization and decomposition involving age- and cause-specific death rates. The study revealed that overall, the population of Calgary enjoys a relatively better health status than the population of Edmonton. Most significantly, it is observed that the difference in health status between the male populations of the two health regions is more pronounced than between the female populations.

The study also found that among all age-groups of the population, death-rates in the age-group 40-64 contributed the most to overall life expectancy, followed by death rates in the 15-39 age-group. This trend is again reflected in the male and female populations even though there is some slight departure in the case of the 
female population. It is observed that death rate in the female population aged 65 and over is lower in Edmonton than in Calgary, underscoring the fact that females aged 65 and over in Edmonton are healthier than their counterpart agegroup in Calgary.

For cause-of-death components, diseases of the circulatory system and injury and poisoning account for a large proportion of the observed difference in expectation of life when the two populations are compared. However, in the case of death rates due to infectious and parasitic diseases and diseases of the respiratory system, Edmonton enjoys some relative advantage over Calgary. The study reveals that more people die of these two cause-of-death components in Calgary than is the case in Edmonton. The same scenario is exhibited in the male population. In the female population on the other hand, death rate attributable to injury and poisoning accounts for the largest proportion of the total difference in expectation of life, and the negative values of deaths attributable to neoplasm, diseases of the respiratory system and diseases of the digestive system indicate that more females die of these causes in Calgary than in Edmonton.

It is clear from the findings in this study that in addition to the observed difference in health status between the general populations of the two health regions, there exist variations in health status among different segments of each population. Most significantly, the relatively high life expectancy of Calgary compared to Edmonton masks the poor health status of some age-groups within the population of Calgary whilst on the other hand, it shows that some agegroups within the population of Edmonton are, after all, healthier than their Calgary counterparts. Therefore, it is not entirely accurate to conclude that the entire population of Edmonton has a lower health status compared to the population of Calgary on the basis of their respective life expectancies. This observation suggests caution in the interpretation of life expectancy as a general measure of the health status of a population.

This study notes also that given its size, the sub-population which would seem to be exerting substantial influence on the overall health status of the population of Edmonton, as reflected in the region's expectation of life is the aboriginal population. This is as a result of the generally low health status of aboriginal people. Furthermore, even though the difference in the level of unemployment between the two populations does not seem to be very much, especially in the case of females, it is worth noting here too that aboriginals constitute a significantly large proportion of the unemployed population in Edmonton. This study is therefore of the view that for Edmonton to catch up with Calgary in terms of life expectancy, measures need to be instituted to improve the health status of the aboriginal population in particular. This view underscores the importance of selective health policies and programs in addressing the health concerns of the different segments of the population of the province. 


\section{Acknowledgement:}

I wish to acknowledge with thanks the insightful comments of Dr. N. M. Lalu of the Population Research Laboratory, University of Alberta.

\section{References:}

Alberta Health, 1996. Report on the Health of Albertans. Edmonton, AB.

Brenner, M. Harvey. 1979. "Unemployment and Health," The Lancet, i : $1290-4$.

Brenner, M. Harvey. 1977. "Personal Stability and Economic Security," Social Policy 3:2-4.

Brenner, M. Harvey. 1971. Time Series Analysis of Relationships Between Selected Economic and Social Indicators, Volume I, Text and Appendices. Washington, D. C.: US Government Printing Office.

Das Gupta, Prithwis. 1993. Standardization and Decomposition of Rates: $A$ User's Manual. U.S. Department of Commerce, (Cat. No. P23-186) Washington, DC.

Frank, J. W. and J. F. Mustard. 1994. "The Determinants of Health from a Historical Perspective," Daedalus: Journal of the American Academy of Arts and Sciences 123(4): 1-19.

Health Canada. 1996. Trends in First Nations Mortality. 1979-1993.

Hertzman, C., J. Frank and R. Evans. 1990. Heterogeneities in Health Status. Canadian Institute for Advanced Research, internal document \#3c.

Marmot, M. G., George Davey Smith, Stephen Stansfield, Chandra Patel, Fiona North, Jenny Head, Ian White, Eric Brunner, Amanda Feeney. 1991. "Health inequalities among British civil servants: the Whitehall II study," The Lancet. Vol. 337.

Marmot, M. G. and T. Theorell. 1988. "Social Class and Cardiovascular Disease: The Contribution of Work," International Journal of Health Sciences 18(4): 659-74.

Shryock, H. S., J. S. Siegal and Associates. 1976. The Methods and Materials of Demography. Academic Press, San Diego. 
Life Expectancy as Indicator of Health Status: A Comparison of Edmonton and Calgary

Sismondo, S. 1978. "The Unaccounted Costs of Unemployment," Perception $1: 33-35$.

Statistics Canada. 1995. Catalogue No. 95-375, p.12, Table 1; Catalogue No. 95378 , p. 12 , Table 1.

Statistics Canada. 1993. Catalogue No. 93-315, p.40.

Syme, S. L. 1994. The Social Environment and Health. Health and Wealth. Proceedings of the American Academy of Arts and Sciences 123(4): 79-86.

Westcott, $\mathrm{G}$ et al (eds.). 1985. Health Policy Implications of Unemployment. Copenhagen: World Health Organization.

Wilkinson, R. G. 1994. The Epidemiological Transition: From Material Scarcity to Social Disadvantage. Health and Wealth, Proceedings of the American Academy of Arts and Sciences 123(4): 61-77.

Received June 1998; Revised June 1999

\section{Appendix A}

\section{Population by Age and Sex for Calgary and Edmonton Regional Health Authorities, 1991}

\begin{tabular}{llrlrrrr}
\hline $\begin{array}{c}\text { Age } \\
\text { Group }\end{array}$ & Males & $\begin{array}{c}\text { Calgary } \\
\text { Females }\end{array}$ & Total & Males & $\begin{array}{c}\text { Edmonton } \\
\text { Females }\end{array}$ & Total \\
\hline $\mathbf{0 - 1 4}$ & 85,040 & 81,245 & 166,285 & 73,055 & 69,080 & 142,135 \\
$\mathbf{1 5 - 3 9}$ & 172,110 & 169,335 & 341,445 & 147,650 & 146,916 & 294,565 \\
$\mathbf{4 0 - 6 4}$ & 94,585 & 93,045 & 187,630 & 80,380 & 81,245 & 161,625 \\
$\mathbf{6 5 +}$ & 24,195 & 34,480 & 58,675 & 25,075 & 35,490 & 60,625 \\
& & & & & & \\
\hline
\end{tabular}

Source: Extracted from Statistics Canada, 1991 Census 2A File. 
K. Boadu

Appendix B

Population by Age, Sex and Age-Specific Death Rates

Calgary Regional Health Authority

\begin{tabular}{crrrrrr}
\hline \multirow{2}{*}{ Age } & \multicolumn{7}{c}{ 1991 Population } & \multicolumn{2}{c}{ Total Number of } \\
Deaths (1989-1993) & Age-Specific Death Rates \\
\cline { 2 - 6 } & \multicolumn{1}{c}{ Males } & Females & Males & Females & Males & Females \\
\hline under 1 year & 6,240 & 5,750 & 240 & 175 & 0.007692 & 0.006087 \\
$1-4$ & 24,300 & 23,865 & 26 & 16 & 0.000214 & 0.000134 \\
$5-9$ & 29,290 & 27,840 & 23 & 15 & 0.000157 & 0.000108 \\
$10-14$ & 25,210 & 23,790 & 26 & 21 & 0.000206 & 0.000177 \\
$15-19$ & 24,355 & 23,620 & 95 & 33 & 0.000780 & 0.000279 \\
$20-24$ & 30,275 & 30,405 & 116 & 45 & 0.000766 & 0.000296 \\
$25-29$ & 37,555 & 38,015 & 179 & 61 & 0.000953 & 0.000321 \\
$30-34$ & 42,365 & 41,495 & 251 & 90 & 0.001185 & 0.000434 \\
$35-39$ & 37,560 & 35,800 & 228 & 125 & 0.001214 & 0.000698 \\
$40-44$ & 30,345 & 29,290 & 254 & 154 & 0.001674 & 0.001052 \\
$45-49$ & 21,385 & 20,715 & 306 & 196 & 0.002862 & 0.001892 \\
$50-54$ & 16,095 & 15,955 & 352 & 250 & 0.004374 & 0.003134 \\
$55-59$ & 14,255 & 14,175 & 527 & 330 & 0.007394 & 0.004656 \\
$60-64$ & 12,505 & 12,910 & 798 & 514 & 0.012763 & 0.007963 \\
$65-69$ & 9,240 & 11,365 & 1,002 & 693 & 0.021688 & 0.012195 \\
$70-74$ & 6,930 & 8,620 & 1,180 & 914 & 0.034055 & 0.021206 \\
$75-79$ & 4,270 & 6,560 & 1,199 & 1,075 & 0.056159 & 0.032774 \\
$80-84$ & 2,290 & 4,295 & 1,102 & 1,281 & 0.096245 & 0.059651 \\
$85+$ & 1,465 & 3,640 & 1,334 & 2,386 & 0.182116 & 0.131099 \\
Totals & 375,930 & 378,105 & 9,238 & 8,374 & & \\
& & & & & & \\
\hline
\end{tabular}

Source: Alberta Health, 1996 
Life Expectancy as Indicator of Health Status:

A Comparison of Edmonton and Calgary

\section{Appendix C \\ Population by Age, Sex and Age-Specific Death Rates Edmonton Regional Health Authority}

\begin{tabular}{|c|c|c|c|c|c|c|}
\hline \multirow[t]{2}{*}{ Age } & \multicolumn{2}{|c|}{1991 Population } & \multicolumn{2}{|c|}{$\begin{array}{c}\text { Total Number of } \\
\text { Deaths (1989-1993) }\end{array}$} & \multicolumn{2}{|c|}{ Age-Specific Death Rates } \\
\hline & Males & Females & Males & Females & Males & Females \\
\hline under 1 year & 5,600 & 5,280 & 227 & 177 & 0.008107 & 0.006705 \\
\hline $1-4$ & 21,150 & 19,830 & 31 & 36 & 0.000293 & 0.000363 \\
\hline $5-9$ & 24,955 & 23,635 & 28 & 21 & 0.000224 & 0.000178 \\
\hline $10-14$ & 21,350 & 20,335 & 25 & 17 & 0.000234 & 0.000167 \\
\hline $15-19$ & 21,115 & 21,250 & 81 & 39 & 0.000767 & 0.000367 \\
\hline $20-24$ & 28,530 & 30,005 & 133 & 52 & 0.000932 & 0.000347 \\
\hline $25-29$ & 33,855 & 33,640 & 214 & 83 & 0.001264 & 0.000493 \\
\hline $30-34$ & 34,725 & 33,610 & 239 & 127 & 0.001377 & 0.000756 \\
\hline $35-39$ & 29,425 & 28,410 & 259 & 140 & 0.001760 & 0.000986 \\
\hline $40-44$ & 23,780 & 23,225 & 265 & 178 & 0.002229 & 0.001533 \\
\hline $45-49$ & 16,995 & 17,290 & 330 & 200 & 0.003883 & 0.002313 \\
\hline $50-54$ & 14,280 & 14,575 & 403 & 255 & 0.005644 & 0.003499 \\
\hline $55-59$ & 13,190 & 13,405 & 600 & 347 & 0.009098 & 0.005177 \\
\hline $60-64$ & 12,135 & 12,750 & 925 & 511 & 0.015245 & 0.008016 \\
\hline $65-69$ & 9,675 & 11,365 & 1,129 & 695 & 0.023339 & 0.012231 \\
\hline $70 \cdot 74$ & 6,635 & 9,000 & 1,282 & 857 & 0.038644 & 0.019044 \\
\hline $75-79$ & 4,570 & 6,795 & 1,334 & 1,096 & 0.058381 & 0.032259 \\
\hline $80-84$ & 2,590 & 4,585 & 1,173 & 1,254 & 0.090579 & 0.054700 \\
\hline $85+$ & 1,605 & 3,745 & 1,475 & 2,421 & 0.183801 & 0.129292 \\
\hline Totals & 326,160 & 332,730 & 10,153 & 8,506 & & \\
\hline
\end{tabular}

Source: Alberta Health, 1996 


\section{Appendix D}

Socioeconomic Information

Calgary and Edmonton Health Regions, 1991

\begin{tabular}{lcc}
\hline Health Region & $\begin{array}{c}\text { Annual Household Income } \\
\text { Less than } \mathbf{\$ 2 0 , 0 0 0}\end{array}$ & $\begin{array}{c}\text { Educational Level } \\
\text { High School or Less }\end{array}$ \\
\hline & $\%$ & $\%$ \\
Calgary & 18.1 & 41.9 \\
Edmonton & 23.3 & 45.8 \\
\hline
\end{tabular}

Source: Statistics Canada, 1991 Census of Canada.

\section{Appendix E}

Population by Ethnic Origin and Sex Calgary and Edmonton Metropolitan Areas, 1991
Aboriginal Origins
Calgary
Edmonton

Males

3,235

7,725

Females

3,570

8,850

Both Sexes

6,805

16,580

Source: 20\% Sample Data, Statistics Canada, 1991 Census of Canada Cat. $93-315$, p. 40. 